\title{
Material Culture and Typology
}

\author{
Marie Louise Stig Sørensen
}

\begin{abstract}
The active and discursive nature of material culture is the subject of this paper. It will, however, be approached from the point of view of typology and in particular the debate about the 'Swedish Typology' (Gräslund 1974). Typology is probably the archaeological method or theory through which the discipline has most explicitly stated its view on the nature of the archaeological object. Inspired by the idea of naturalised epistemology as the basis for understanding how knowledge is constructed within the sciences (as discussed by Thomas 1996: 194), it is here argued that what we do, as archaeologists, is of importance rather than the theorising about our actions. Through a discussion of typology as expressed in archaeological practice, this paper will propose that the relationship between the object and typology is much simpler and more complex than our habitual use of the concept tends to suggest. It is proposed that the creation of typologies reveals the quite decisive influence which the object has upon the archaeological constructions. Typologies, moreover, are intimately connected to prehistoric production strategies. It is the relationship between these two dimensions of typologies, that we must understand in order to fully realise their potentials and understand their roles in archaeological practice.
\end{abstract}

Marie Louise Stig Sфrensen, Department of Archaeology, University of Cambridge, Downing Street, GB-Cambridge CB2 3DZ, Great Britain.

As a discursive device, this paper will outline a fictional debate between three important theoreticians within Scandinavian archaeology: Montelius, Müller and Malmer. My own reflections upon the problems and potential within the concept and theories of typology will be added to this (Sørensen 1989). This addition aims to update the fictional debate by including the notion that material culture is active. In particular it will be considered whether the archaeological concerns indicated by references to, on the one hand, typology and, on the other hand, material culture as active, can be reconciled. The fictional and conjectural character of the reconstructed debates makes this a rather informal discussion. It is, however, concerned with one of the most central questions within archaeology as a discipline: are patterns in the material culture the result of human action and therefore essentially meaningful? This paper will not aim, however, at a finite discussion of archaeology's creation of its object, nor will it consider its analytical procedures per se.

\section{TYPOLOGY AS A TOPIC}

Variations within material culture are meaningful on different levels. Of particular importance, the physicality of objects means that they transcend the life of individuals and provide the material environment for the 
reproduction of society (Miller 1985). Material categories, also, "represent an order that is imposed upon the world through the creation of material objects. As such they are part of the overall creation of cultural order, and may be used for the study of the social and material relations of which they are a product" (Miller 1985:10). It is therefore possible to argue that our created typologies, despite their constructed nature, are to some extent a reaction to and the result of meaning in the prehistoric society (Sørensen 1989). While this relationship has been discussed theoretically, in pratice it is usually only acknowledged intuitively rather than used explicitly in the employment of typologies. The exciting and complex relationship between our construction, the object, and the prehistoric categories is accordingly not properly explored. It is either ignored or buried in methodological directions for the formal procedures, through which the 'correct' entities and order may be recognised. Alternatively it is denied through various theoretical arguments, which present the prehistoric object/type as our own contemporary construction. Much of the discussion has accordingly focused upon the question of the existence of types and our methods/ability to recognise them, rather than using as a starting point that objects are products of human activities and play an active role in the production of meaning and the creation of tradition. Through their roles in communication, objects embody codes and categories. They are also part of networks of relationships created between objects, actions, meanings, and situations, all of which are continuously changing through human agencies. Another important characteristic of the material object is its physicality, which often gives it relative permanence and duration, creating new situations which may be unrelated to its original meaning and use. It is due to these characteristics that ideas such as the 'biographies of things' (Appadurai 1986) have gained influence (e.g. Edmonds 1995). This has firmly introduced the notion of the life of objects, of them undergoing changes in their use and meaning, and of past meaning potentially affecting future conception. These subtleties in the character of objects have, however, hardly influenced our typologies or the ways we view them. Thus the potential influences behind the making of an object and its changing categorisation through its 'life', are still ignored. The object in itself, as opposed to its existence as a type, is basically considered an entity without a context of becoming and being. Objects, however, are not produced in a void, and we need to comprehend this when we interact archaeologically with these items of material culture. Recent discussions of the nature of material culture have paid attention to some of these dimensions. For instance, Miller emphasises that "artefacts, as objects created and interpreted by people, embody the organisational principles of human categorisation processes" (Miller 1985:1). Awareness of these properties of the object must influence our typological theories and practice.

This paper attempts to explore this way of seeing the object, aiming at some resolution of the tension between the traditional concept of typology and a post-processual approach to the object. This tension arises from attempting to combine a critique of the past's reality with the recognition of meaning, and from the simultaneous emphasis upon the social construction of meaning and upon the active and creative role of objects.

Meanwhile, let us briefly consider why the concept of typology is still of interest. What is it that we do not understand about typologies, why do we desire to employ this concept, and for what is it used? Typology is still of central importance on a very fundamental level, since in practice it is one of the main tools used to create both order and direction, i.e. time, within archaeological data. Given this, the nature of this order must be considered: where does it come from and which factors cause the variations in the material? It is these types of questions that give 
rise to the radical differences, disagreements and conflicts within discussions of typology. The main impression is, however, of a lack of insight into the relationship between the object, which is used in typologies, and the social reality that it emerges from. As a discipline we still do not understand this relationship, and therefore we do not comprehend the nature of the object that we react to, nor the order that we create. Basically, we do not fully know what it is that we do in response to the object.

\section{DISCUSSING TYPOLOGIES:}

\section{CONSTRUCTION, EVOLUTION, OR INTENTION}

Our dilemma, if we are willing to recognise it as such, is found within our perception of humans and their material products, or rather, material expressions; in their relationships and mutual interaction. Objects are not like agents, and they do not act of their own will; but there are nonetheless ways in which they actively and dynamically affect society and direct human activities. The problem arising from the presence of humans - agency - behind the object, is clearly felt within the typological debate. For a long time the most heated arguments have therefore been about whether typologies are created by the archaeologists or are revealed just by them, that is, do typologies have some relationship to categories or meaning within prehistoric society, are they real? One approach argues that typology is purely a classificatory tool to create order in large amounts of data and to facilitate comparison between different groups of objects (e.g. Ford 1954; Hill \& Evans 1972). This view assumes that typologies are arbitrary in relationship to the prehistoric society, that is, the order that is created has no relationship to prehistoric meaning or classification. The other main approach states that typologies overlap with prehistoric entities. Some argue, for example, that types correspond to prehistoric ideas or mental templates (Krieger 1944), while others see them as functional responses or expressions of 'culture', fashion or style (e.g. Sackett 1973:320321). Still others see them as the result of random, inevitable variations during production (Clarke 1970:9). Those who accept that our order has some relationship to the past are further divided in their view of how typologies are generated. The main division is between those who see typologies as evolving mechanically on the basis of inherent properties, which are latent in the object's form and elements (i.e., an essentially evolutionary view), and those who insist that the order is the result of human action and intentions. Within these approaches, the archaeological task is to establish the direction of change, date the beginning of the typology, and identify the types (Montelius 1903:1617).

Recent theoretical discussions would identify the former approach as part of the attempt at an objective, scientific archaeology, which holds that our concepts, entities and analyses can be value-free and un-influenced by wider concerns and questions. The latter approach contains arguments which belong within this same scientific school, as when it is argued that true prehistoric types are being uncovered. But it can also embrace other epistemological views, including idealistic, normative, and subjective arguments. This approach assumes that both the prehistoric context of production and the relationship between the object and its analyst are determinable and absolute: there is one meaning and one understanding to be reached. Therefore, although the object is assigned meaning, at the same time it is entirely passive and its meaning is absolute. This view rests on an assumption about a right, correct type, which exists as an independent entity clearly delimited and separate from others. Furthermore, the type is assumed to exist both in the past and in our analytical constructions, and there are no differences between either the type or its meaning in these two contexts. This approach largely seems to work through in- 
tuition and at times empathy. Its results (i.e. types and typologies) often appear methodologically vulnerable, as there is no analytical account of how they are reached. For various reasons, none of the above approaches recognises the 'otherness' of the past, nor do they attempt to reconcile this 'barrier' with our experience of interaction with the physical remains of the past. They do not properly appreciate the complexity involved in how the 'type' and its meaning are always constructed in a special cultural context, which involves the object as well as the observer.

The question we should ask now is whether these two approaches provide a correct and constructive perception of the archaeological object and of our discipline: do we have to choose between understanding typologies as either arbitrary or as absolute and definite?

\section{OBJECTS OF SIMILARITIES AND DISSIMILARITIES}

This critique of archaeologists' discussions of their typologies could be continued and expanded in various directions. Let us here instead return to the background of the problem: the similarities and dissimilarities between objects over time. Discussions of typology have typically treated similarities between objects or elements in a rather simplistic manner. One may even argue that the discipline has largely considered this phenomenon as a mechanical, analytical problem, rather than something which in itself needs to be fully appreciated if not exactly explained. To some extent the discipline has lost its ability to wonder why the world is not chaotic. We simply assume this to be the 'natural' state of things; similarity and order are to be expected rather than seen as a result of behaviour and its implied significance. For instance, Malmer and others like him see similarity between objects as essentially unproblematic and unsurprising, reducing it to a starting point for further inferences: "Physical similarity entails a probability of every other form of similarity, i.e. similarity in respect of time, use, name and environment. A correctly defined type corresponds to a concrete historic situation" (Malmer 1963:264). Similarity almost means identical, and the problem is no longer to understand similarity or dissimilarity but to measure where similarity stops and dissimilarity begins. And since such similarity is not primarily based upon consideration about production and decisions - in short the human practices and strategies resulting in the product - it becomes a measured, objective, quantifiable similarity in which there is no consideration for the intentions, values and meanings which the original producers and users associated with the object. Similarity is neither recognised as a quality nor problematised as a practice. Typologies apparently become objective, and they use arbitrary - or in Malmer's terminology, rationalistic - type definitions and limitations (Klejn 1982; Malmer 1984: 264). Malmer, for instance, sees typology as being about the selection and definition of independent elements. To Malmer, typology is furthermore a method for clarifying links within archaeological evidence, for ascertaining connections between types, and for interpreting types. Typology is also not just about artefacts: as a method it encompasses all comparative analyses of types (Malmer $1962,1963,1984)$. Thus it applies equally to all elements, such as artefacts, monuments, settlements, social forms and distribution patterns. The further development of this rationalistic approach is interestingly suggested by Malmer's recent study of weight and value systems in the Bronze Age (Malmer 1992). This study sees the quantitative similarity between objects, such as the bronze figurines, as the meaning. Similarity in itself is the value, and no room is left for the possibility that similarity is a result of what is emphasised in the production of these objects, that it is the result of a practice rather than the aim per se.

These reflections have led us to another 
junction, where we can again either go on expanding and elaborating upon the variations between the different approaches to similarity, or, as this paper will do, ask what those differences are about. Do the apparently decisive differences go deeper than the formal and the methodological? Might it be the case that the differences that have been outlined are the result of epistemological disagreements between the archaeologists as to 'how the world ought to be', rather than real differences in their working practices and interaction with the archaeological material? If we turn away from the theoretical polemics and look instead at what our practice is and how the typologies, which have been created, have functioned, might we then gain another insight into the problem? It is immediately obvious that the practical impact of different typologies does not depend upon what those who constructed them said they meant. One may therefore ask whether we in our archaeological practice often understand something about material culture which we as yet do not comprehend theoretically nor articulate analytically.

As a departure point for our further consideration let us therefore go back to the earliest debates. Let us remember the poignant points in the discussion of what was then nicknamed the 'Swedish Typology', and at the same time remember how well Montelius's typology has functioned, as its use has remained unchallenged for more than 100 years.

Montelius's typological division of the Scandinavian Bronze Age of 1885 formally appears to rest upon and suggest the gradual evolution of the form of certain objects over time. Amongst its other implications, this means that the dating of single objects becomes independent of find-context and a more central element of archaeological research. Montelius later explained the systematic chronological evolution of the objects through an analogy between the product of human labour and the evolution of the species
(1899). It has been proposed that this explanation is a rationalisation which occurred partly in response to Müller's critique of 1884 (Gräslund 1974). Montelius was familiar with evolutionism and the developments within the natural sciences, when he began developing his typological ideas. Thus, theoretically this could have been the principle that affected his interaction with the material - although the possibility alone does not demonstrate that it was on this basis that the division of types and their order was established. Müller maintained that this could not have been the case. He said that the systematic and chronological location of the single object within a typological series was only possible because we already knew their findcontexts, and that such prior knowledge could not be suppressed (Gräslund 1974; Müller 1884; Sørensen 1989, forthcoming b). Gräslund has shown that Montelius in fact had access to information about the findcontext for the majority of items arranged in his typological seriations, and he argues that the division of the material could have been reached without the use of typology (Gräslund 1974:175-192, 1987:71-84). The theoretical possibility of either evolutionism or find-context being used to influence or even create the classification does not, however, establish how Montelius created his order, nor how the object and the find-context interacted in his practice. Let us ask him to explain what he did.

Montelius: Of course, the find-context is also, actually equally, important for the chronology; but one can know the object in a different way. The typology comes from the objects if one knows them well enough; if one sees all of them-or most of them - then one finds their typology.

Müller: Then the typology is the work of an artist. You say that one needs experience to see it, to make it - but what is that experience but the eye of an artist? The inference from the find-context that is the work of the 
archaeologist.

Montelius: No, the experience is training, not empathy. The material has order in it, and familiarity will train you to find that order. The more objects of a type you have seen, the better you will be able to recognise their unique family traits. This is about observations, not about feelings! Archaeological typologies are real, they are not creations like the work of artists. We work like natural scientists, and typology is to us what taxonomy is to them - we look at the elements and order them through their likeness.

Miiller: But either you accept their likeness because the find-context shows them to be similar, or, like you do, try to argue that objects have essential properties that behave, and that we can find the order in their behaviour. If you can see into the heart of the object, then you are an artist!

Montelius: No! I am a scientist, and typology is my taxonomy. I found the order in the bronzes and laid them out, and the same order is found everywhere - what more proof can we want? The Bronze Age chronology is true. You, you search beyond the realm of science, you probe beyond the relevance of questioning ... You are the artist!

Müller: I wish I was! But I cannot see the object like you do. You feel its logic and recognise its essence - but that is not a method, and it is not possible to divide the material with this knowledge alone. I know there is art in the object, but that is not enough for us. As archaeologists we must temper our feelings with logical inference. We must always remember that our knowledge of objects is not neutral. As archaeologists our most important evidence is the assemblage, the object is secondary. Observation and comparison are our tools. And it is the contexts - not the object - which provide the framework for our study.

Montelius: Your arguments daunt me, and I accept the importance of the assemblage. But can you not see the importance of the object? The find-context alone has shown us that bronzes from different periods look different, and yet they also have similarities - they are related to each other! Is this not an important observation, does it not have an independent use?

Muiller: I cannot understand how the object alone, on its own, can be scientifically important. Through typology alone we will never reach beyond the limitations of the object — we aim beyond that. Our aim is not to understand a single type, but to understand the truth about society. There are humans behind the objects, and they are not as predictable as nature. Your chronological division is right, I grant you that! But if you were not guided by the find-context, then I don't know how you reached it, and most certainly neither do you! (1).

In the discussion of the 'Swedish Typo$\operatorname{logy}$ ' Montelius argued for the object and its meaningful typological ordering, while Müller believed in the find-context (fundsammenhangen) and saw typology as derived from context. Montelius's typological division has since been tested in many different ways both within its own logic and in comparison with independent data and absolute dating methods, and we have not been able to demonstrate that his division is wrong, that it is not 'true'. "'I see that they read my Tidsbestämning' commented Montelius happily in 1904 when the magnificent grave from Håga in Uppland was discovered: the objects there are typical of his Period 4." (Gräslund 1986:7). In the terminology of Malmer the division has withstood repeated attempts at falsification. Thus we are in the interesting situation of, on the one hand, having a typological division of the material that seems to be correct on some level and therefore to have some kind of relationship to the order in the material culture of the Bronze Age, and, on the other hand, we have different arguments about the basis of this typology. As regards the latter, we have both Montelius's own attempt at an explanation 
and Müller's critique, as well as many later contributions to the debate. Rather than following these attempts at explaining why typologies can be made, let us, instead, go further back and observe Montelius's practice: how did he construct the typologies?

Montelius was apparently able to construct his typological series for the Bronze Age on the basis of his enormous knowledge of the material (Gräslund 1986:12, 15; Montelius 1885 preface 1903). He had seen and was familiar with the majority of bronzes found in Europe at the time. In addition he had empathy, feelings for the material; intuitively and subjectively he saw the differences, similarities and connections in the material, and he was able to use this knowledge in a systematic manner. That is the kind of language, the types of adjectives, which we need to account for what Montelius used to create his series. He refers to the development/evolution of types, and he comments upon how one can follow a type as it ages through time (Montelius 1885:48). He describes his method, the typological method, in the following way: "Firstly, I have studied separately each of the most important series of weapons, tools, ornaments and [hanging] vessels as well as decoration, in order to get to know the course of development and to see in which order the types, according to their own criteria, follow upon each other" (ibid. 51). He states that types have internal connections and develop from each other (ibid. 9), and that this provides us with the opportunity for investigations that are different from those made possible by find-context. There are only a few clues as to the observation which Montelius used to establish his series (beyond the evidence provided by find-context). He states that the typological series are mainly based on the internal characteristics (Sw. inre kännetecken) of each type (ibid. 79), but these are only vaguely suggested by the description of types, and only slightly more clearly hinted at by the two accompanying illustrations of the deve- lopment of an element of a type (see fig. 1).

In later papers biological analogies are used to indicate that types have essential properties. He uses, for example, concepts such as proto-type or natural forms, from which the other types developed, and he indicates that further inspection will reveal the differences between the often similar proto-type and the final type of a series (Montelius 1903:17). He also argues that we, like natural scientists, must show special attention to rudimentary elements of a type, elements which once were functional but which over time have lost their practical function (ibid. 17). Without the associated jargon, such observations were used already in the 1885 description of types, as in the case of socketed axes: "Large, usually circular at the top with many transverse, narrow ribs, reminiscent of the thin cords used to attach the haft to the axe, of which these socketed axes developed" (Montelius 1885:53). It is, however, not at all clear what he systematically or analytically uses to guide his observations - although anyone 'familiar' with the material recognises what he refers to!

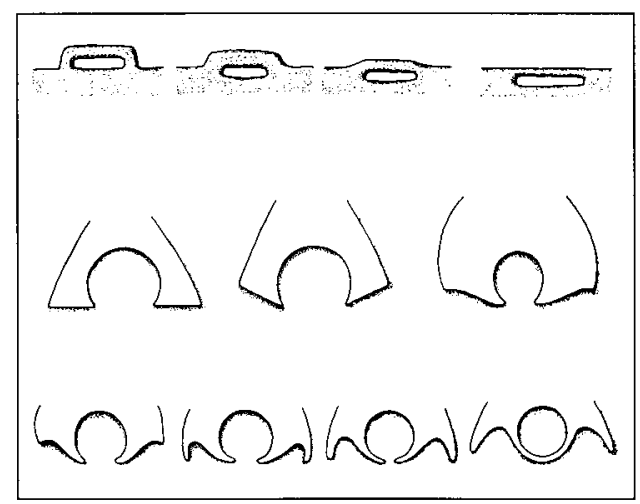

Fig. 1. The two illustrations from Montelius 1885 showing the development of elements, which provides a subjective impression of "his" typology (based on Montelius 1885, figures on p. 54 and p. 76). 
So the key seems to be knowledge of the material; but what does that imply? Here it could have been interesting to hear a discussion between Müller and Malmer in addition to the exchanges between Müller and Montelius.

Müller: To understand the material, we must know it in its entirety. Then it will guide us. We must embed ourselves in it with artistic empathy, and it will show us its secrets. Then we can work scientifically and propose regularities based on comparison and induction.

Malmer: No, I can construct typologies on any random selection of objects - whether they are old or contemporary, standardised or diffused. This is the typological method: to find the order in the material. Not to impose an order, but to create a rational order from the degrees of similarity and dissimilarity between the objects.

Muiller: But that kind of order is already established through the find-context, our finest archaeological method. The direction it provides predetermines the typology.
Malmer: No, that limitation may be relevant to Montelius's use of typology because he still worked mainly intuitively rather than objectively and scientifically. But this is not an accurate understanding of typology. Typology can be made for anything independent of its context - in fact, the type itself can be considered a context. Typology is the ordering of types on the basis of degrees of similarities and dissimilarities, and the study of their relationships.

Müller: Yes, in practice the study of findcontext and typology cannot be separated; but the study of similarities can not be detached from our knowledge about the object we study, and the find-context is therefore primary. The type is not the same kind of context as an assemblage. The assemblage gives us the time, the event, the things which existed together. The typological seriations are thought-experiments; their solidity comes first when they are combined with other evidence.

Malmer: Typology is theory. It refers to the scientific study of similarity and dissimilarity - to the systematic study of attributes

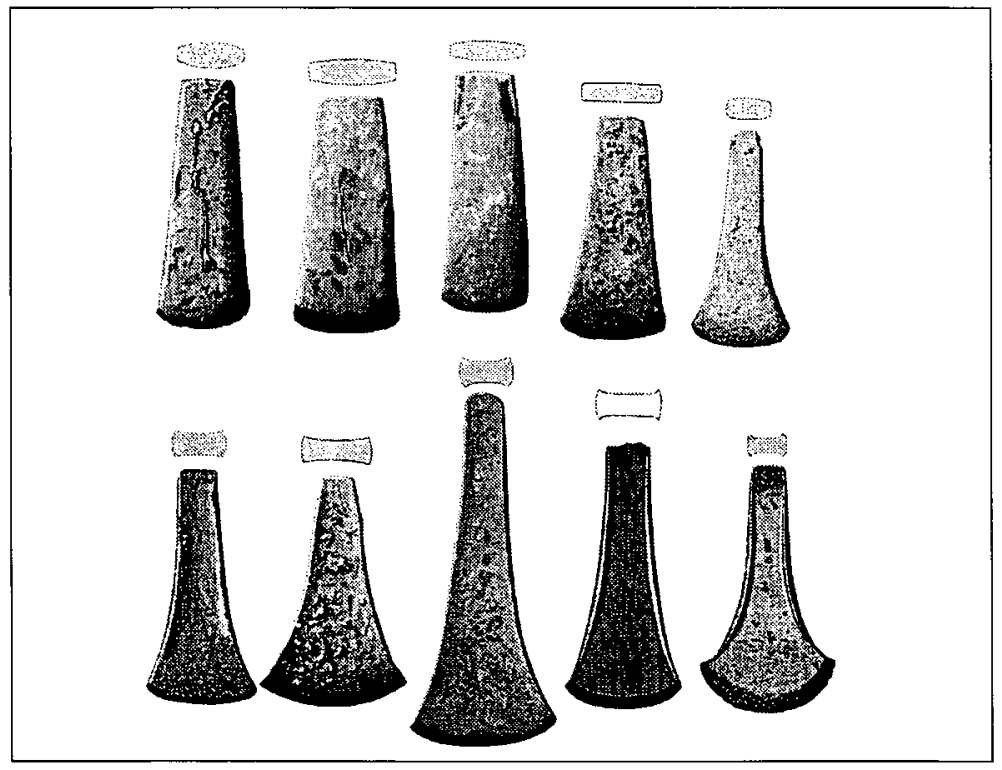

Fig. 2. Montelius's illustration of the typological seriation of bronze flat axes (based on Montelius 1903, figs. 41$50)$. 
and their relationship. The find-context is a study of association - useful and of primary importance for archaeological research, but not a theory.

Müller: But you do not choose to make a typology of pots from, say Sudan and Sweden; you make a typology of Swedish battle axes. The theoretical typologies are irrelevant: it is the typologies we use that matter, and they are constructed with knowledge. Where do we look for similarity and dissimilarity and what do we look at? The theory is not explicit: it is our total knowledge of a material that guide us towards recognising its order. The order is also only an approximate order, for there is much changeability in human life. Archaeology is not science, our knowledge is not objective, but neither are we like history. We are a third subject and we learn from observing and comparing.

Malmer: Yes, archaeology is a distinct discipline. It must therefore define its methods and theories, and principal amongst these is typology. You give too little credit to the object. Comparison can be both relative and absolute (2).

Malmer has defended and in significant ways further elaborated typology as a theory (see Klejn 1982 and Klejn in Burström 1994; for a critique of this development see Gräslund 1974:25-31); but it is still legitimate to ask: what is the practical experience, knowledge and understanding that affects his hypothesis, the selection of variables to be measured, and finally the definition of his types? Müller would insist that it is knowledge of the material that influences Malmer's selection, that decides what is measured and what is not. Here it is relevant to introduce an often ignored fact about Montelius's typologies: while he constructed a valid division for the Bronze Age as such, he did not create typologies for all bronze items of the time period. He himself made this clear: "... it is necessary to emphasise here that it is only a question of types which really are characteristic of a particular period, not with forms that are so simple that they remained unchanged through many periods" (Montelius 1885:85). The items that are not included are typically either unique, special objects, such as some items of horse-gear or wagon decoration, or they are extremely simple and 'informal' items such as pieces of bronze sheet worked to resemble razors (Sørensen 1987, 1989). The former, in their uniqueness, can not be subjected to typological treatment, and the latter, in their simplicity, lack the distinct elements used for typologies. However, due to these variations in the 'formality' of the objects, Montelius' typological division of the Bronze Age quite simply ignores part of the contemporaneous material and selects for typologies only those objects that are most suitable. Such selection, Müller would say, is of course done with a knowledge of the totality of the material and its physical characteristics. This selection also has implications for the extent to which it can be argued that this was constructed as an evolutionary typology, since Montelius pays no attention to the apparent static or stagnant nature of some objects; this phenomenon did not seem to interest him.

Montelius's actual practice, through which he reached his typological division, suggests that Müller is right in his basic critique of what is behind our typologies. Typologies of lasting importance are built upon extensive knowledge of the material, irrespective of the investigations' apparent methodological or theoretical appearance. This, however, is not the end of our questioning, for we still have to consider what Müller's emphasis upon knowledge of the material actually means. Does it not imply that typologies are either just our own contemporary constructions or the belief that we have in fact found the type-concept of prehistoric society - in which case we are back at the same simple choice between arbitrary or absolute. The emphasis upon the knowledge of the material does not imply this. It simply means 
that through extensive comparison it becomes possible to recognise that the material in its physical proportions and compositions consists of repetitions, similarities, variations, that some elements vary and others remain constant. Material knowledge means that one is familiar with an assemblage, but it does not signify understanding as well. This distinction between familiarity and understanding is, however, rarely seriously considered, and the former is often pretentiously presented as if it was the latter. We must accept that the typologies, of course, are our constructions. They are established on the basis of what we were able to see and recognise within the objects; but at the same time we should emphasise that they are constructed in response to a material and visual medium. And this medium, like a text or a language, is a coherent complex which in the past was understandable on some level. In its production it was neither chaotic nor absolute, and in our interaction with it we must not restrict our understanding to these two extremes. The prehistoric interpretation and reading of the object and our re-interpretations of the same, do not of course use the same cultural references; but since understanding could occur in the first place, there must be structures laid down in the material which have influenced its (re)production. In fact, one can argue that Montelius's typological and chronological division of the Scandinavian Bronze Age has been so highly successful exactly because this material is unusually clearly structured. Gräslund has argued that during the Bronze Age there was a constancy in manufacture that makes it possible for the archaeologist to recognise artefact types, and that the 'typological project' was facilitated by the distinct cultural unity of the time period and the striking continuity and high level of stylistic interdependence of the objects (Gräslund 1986:11, 14). Referring to Bertil Almgren, he further argues that, "... the material within each period is marked by a unified style which in its turn gains its character from the type-stability which lies behind the formation of periods. Montelius's Bronze Age periods, in other words, are not a purely arbitrary abstraction but reflect a certain factual periodicity in craftsmanship/artistic production" (ibid. 14). The same characteristics have been used by Sørensen to argue that bronzes during the Late Bronze Age played a special role which affected, and is expressed in, standardisation and structuration of their production and consumption (1987, 1989).

Thus, our typologies do not reveal a specific meaning in the past, nor do they relate to an 'original' type-concept or lack of the same; rather, they react to those structures which in the past influenced the production and reproduction of the object. It is with regard to these issues that so-called post-processual archaeology can contribute constructively to the debate on typology. It provokes us to show greater attention to processes of categorisation and logic, and to understand these as discursive rather than mechanical practices. Typologies come from the dynamic interaction between agents, society, tradition and the materiality of action. Such emphasis makes it possible to comprehend the diverse and dynamic nature of typologies: they are changeable, they can cease, they may be more or less diffuse, they only exist for certain types, etc. There are in fact numerous ways in which we qualify our practical use of the type-concept and the typological method (as already Montelius did), and this should long ago have shown us that our abilities to establish usable typologies are the result of past societies reproducing a selected part of their material surroundings in a structured manner.

\section{TYPOLOGY AS STRATEGY}

In an attempt to capture some of these variations, it has been suggested that typologies are the expressions of reproduction strategies (Sørensen 1989). In other words, typologies are the result of a systematic and 
structured change of a certain range of objects over time. Through this, typologies reflect certain emphasis and strategies made by the society in its (re)production of itself. This means that the importance of typology does not primarily lie in chronology, but rather, in the insights it gives to cultural values and choices (ibid. 63).

Using this perspective to study the bronzes from the Late Bronze Age in Scandinavia, it is proposed that different categories of objects were subject to distinct reproduction strategies resulting in more or less tight typologies. It is also demonstrated how these variations correspond to other structures and values, such as male and female (Sørensen 1989:72). Such an analysis aims neither at the discovery of real prehistoric types nor at the recovery of meaning. Responding to the typological similarity between objects, it nonetheless demonstrates that objects in the past were conceptualised differently, and that their manner of reproduction produced categories resulting from and attracting further meaning. The proposition that typologies can be usefully comprehended and studied as reproduction strategies, has been further elaborated by Jakobsson in an interesting study of Viking Age sword typology (1992). This study is particularly innovative in its demonstration of how the reproduction strategies can be utilised to access the values and norms affecting the object. The study argues that the design principles dictating the sword typology are only understandable if one accepts that a symbolic value, linked to the physical form, was involved in its production (ibid. 115-119). In other words, the essence of what constitutes and gives meaning to a sword (that which made an object a sword and of a certain importance to the Vikings) affected how the sword was designed. Such studies use the approaches and the insights gained from the earlier typological debates; but they also add a dimension to them by focusing upon the communicative role of material culture.

\section{ARCHAEOLOGY AS MATERIAL RESEARCH: A CONCLUSION}

The similarities and differences which we use to create types and typologies, are meaningful messages in the societies we study. They are, for instance, used to mark, express and objectify signals, values, norms, hierarchies, identities and social groups. Meanwhile, material objects don't just become, they are produced, and this does not happen meaninglessly and without context. As archaeologists we react to the object and its relationship to other objects; but the distance between 'them' and 'us', between the observer and the observed, and between our knowledge and theirs, means, that our order (our typologies) can not be identical to theirs and thus does not overlap in meaning and content. In response to this problem, discussions of typology have focused upon the formal definition of types, their relationships and the nature of their 'existence'. As a consequence, the object in itself becomes fundamentally meaningless, and the relationship between us and the prehistoric object of study is simplified. These discussions have reduced typology to a matter of either-or existence, rather than emphasising the unavoidable observation of similarity/dissimilarity between objects. Most importantly, this ignores the potential for insights into how meaningful, familiar and structured surroundings were created. Differences and similarities between and through the objects were understood and employed in the formation of the society at any one time. If we refrain from intellectual and analytical involvement with these structures, then one of the most fundamental aspects of the way in which society creates and recreates itself is lost. The distance and the shifts between our typologies and their original structures are insignificant - although not reducible - in comparison with the importance of incorporating these structures into our analysis and reinterpretation of those societies. It is important to accept that there ".. is no 'true' typology or taxo- 
nomy but, equally, the producers cannot be disestablished as the creators of the order under study and such order cannot be reduced merely to the hypotheses of the analyst. A classification, whether constructed by the producer or the analyst, captures only a part of the order embedded in material categories and is always from a particular perspective. However, this is just as significant for the society which produces and uses ... as for the external analyst" (Miller 1985:11).

While we do not understand what typologies mean or how they arise, we have been able to construct them successfully from the archaeological record for more than a hundred years. In this interaction between the archaeologist and material culture, the former brings knowledge, social context, etc., but the object also injects an influence. It cannot insist on an interpretation, but it seems to be able to inspire and affect understanding. Current notions of 'networks of resistance' (Shanks \& Tilley 1989), resonance between an interpretative statement and its object (Hodder, pers. comm.), and the logic of material culture (Sørensen 1987) all refer to an object that is active in our interpretative practice. The nature of and reasons for such resistance to our interpretations have not as yet been sufficiently debated, and clarity and comprehension of this relationship are most certainly needed. Meanwhile, the relationship between knowledge and object appears in our practice to be dialectic. This means, furthermore, that the objects of study can not be reduced to an arbitrary or rational entity; on the contrary, the object is our only possibility of contact with the past.

Despite the danger of fetishism, archaeology, as Malmer argues (1963:11), should be material research (Sw. sakforskning) - the study of the object and the materiality of action and meaning. But it is critical that the material form is also related to its social and cultural context. Scandinavian archaeology is founded on and further grounded in such material studies. Yet in order to understand the past as dynamic societies with active, involved people rather than merely as a rational material record, it is important to add to this tradition the heritage from Müller and to explore more aspects of the object and our interaction with it. This makes archaeology a far more difficult discipline to work within but it also gives it a different relevance for contemporary society, a greater sensitivity to other cultures, and a unique position as a discipline studying societies through the materiality of action.

\section{NOTES}

1) This exchange is based on Gräslund 1974, 1986, 1987; Montelius 1885, 1903; Müller 1884, 1897, 1907; and Sørensen forthcoming b. This fictional debate, rather than a historiographic analysis, was constructed to bring out the differences in how Montelius and Müller interacted with the archaeological record. I propose that Montelius had the skills and ability to construct the 'right' order out of the various archaeological information, but Müller potentially understood the nature of archaeological evidence in a more sophisticated manner. Montelius's working methods are in fact difficult to extract from his papers (see also Gräslund 1986), and a more profound understanding of his typology is likely to depend on an analysis that moves beyond his published papers. Müller, in contrast, published extensive reflections upon both the nature of archaeological evidence and archaeological interpretations (e.g. 1884, 1907).

2) This exchange is based on Gräslund 1974, 1986, 1987; Malmer 1962, 1963, 1970, 1984, 1988; Müller 1884, 1897, 1907; and Sørensen forthcoming a and $b$; and Malmer's comments on my lecture at the Dept. of Archaeology, Stockholm, October 1995.

English revised by Laura Wrang.

\section{ACKNOWLEDGEMENTS}

I would like to thank Mats Burström for inviting (and challenging!) me to give a talk on typology at the Department of Archaeology, Stockholm University. I am grateful to both him and Anders Carlsson for their stimulating comments on this topic. 


\section{REFERENCES}

Appadurai,A.(Ed.) 1986. The Social Life of Things: Commodities in cultural perspective. Cambridge: Cambridge University Press.

Burström, M. 1994. An Ivory Tower in Archaeology? A conversation with Leo S. Klejn. Current Swedish Archaeology, Vol. 2: 7-12.

Clarke, D. L. 1970. Beaker Pottery of Great Britain and Ireland. Cambridge: Cambridge University Press.

Edmonds, M. R. 1995. Stone Tools and Sociefy. Working stone in Neolithic and Bronze Age Britain. London: Batsford.

Hill, J. N. \& Evans, R. K. 1972. A model for classification and typology. In: D. L. Clarke (Ed.) Models in Archaeology. 231-273. London: Methuen.

Ford, J. A. 1954. The type concept revisited. American Anthropologist 56, 1:42-54.

Gräslund, B. 1974. Relativ datering. Om kronologisk metod i nordisk arkeologi. TOR XVI.

1986. Oscar Montelius and his Chronology of the Bronze Age. In: O. Montelius 1986. Dating in the Bronze Age with special reference to Scandinavia. 7-15. Kungl. Vitterhets Historie och Antikvitets Akademien.

- 1987. The Birth of Prehistoric Chronology. Cambridge: Cambridge University Press.

Jakobsson, M. 1992. Krigarideologi och vikingatida svärdstypologi. Stockholm Studies in Archaeology 11. Stockholm.

Klejn, L. 1982. Archaeological Typology. B.A.R. International Series 153. Oxford: British Archaeological Reports.

Krieger, A. D. 1944. The typological concept. American Antiquity 9: 271-288.

Malmer, M. P. 1962. Jungneolithische Studien. Acta Archaeologica Lundensia. Lund.

- 1963. Metodproblem inom järnålderns konsthistoria. Acta Archaeologica Lundensia. Lund.

- 1970. Comments on "On Artifact Analysis". Norwegian Archaeological Review 3, 42-29.

- 1984. Arkeologisk positivism. Fornvännen:271274.

- 1988. Konstanter och variabler i det förhistoriska samhället. Fornvännen:89-97.

1992. Weight systems in the Scandinavian Bronze Age. Antiquity 66, 377-88.
Miller, D. 1985. Artefacts as categories. Cambridge: Cambridge University Press.

Montelius, O. 1885. Om tidsbestämning inom bronsåldern med särskild hänsyn till Skandinavien. Kongl. Vitterhets Historie och Antiqvitets Akademiens Handlingar 30, ny följd, 10.

- 1899. Typologien eller utvecklingsläran tillämpad på det menskliga arbetet. Svenska Fornminnesföreningens Tidskrift 10, 3: 237-268.

- 1903. Die Typologische Methode. Die älteren Kulturperioden im Orient und in Europa, I. Stockholm.

Müller, S. O. 1884. Mindre Bidrag til den forhistoriske Archaeologis methode. Aarb $\phi$ ger for Nordisk Oldkyndighed og Historie, 161-216.

- 1897. Vor Oldtid. København: Det Nordiske Forlag.

- 1907. Nationalmuseet. Hundrede aar efter Grundlaggelsen. København: Folkeoplysningens Fremme.

Sackett, J. A. 1973. Style, function and artifact variability in palaeolithic assemblages. In: C. Renfrew (Ed.) The Explanation of Culture Change: Models in Prehistory. 317-325. London: Duckworth.

Shanks, M. \& Tilley, C. 1989. Questions rather than answers: reply to comments on archaeology into the 1990's. Norwegian Archaeological Review 22:42-54.

Sørensen, M. L. S. 1987. Material order and cultural classification; the role of bronze objects in the transition from Bronze Age to Iron Age in Scandinavia. In: I. Hodder (Ed.) The Archaeology of Contextual Meanings. 90-101. Cambridge: Cambridge University Press.

- 1989. Looking at peripheries. The reproduction of material culture in late Bronze Age Scandinavia and England. In: H-Å. Nordström \& A. Knape (Eds) Bronze Age Studies. 63-76. Stockholm: Statens Historiska Museum.

- forthcoming a. Mats P. Malmer: an intellectual biography. In: T. Murray (Ed.) Archaeologists: a Biographical Encyclopedia. New York: Garland Press.

- forthcoming b. Sophus Otto Müller: an intellectual biography. In: T. Murray (Ed.) Archaeo- 
192 Marie Louise Stig Sörensen

logists: a Biographical Encyclopedia. New York: Garland Press.

Thomas, S. 1996. Archaeologyand Subjectivity. An Analysis of the Place of Subjectivity in Interpretative and Writing Practices. PhD Dissertation, Cambridge University. 